\title{
A Critical Discourse Analysis of News Reports on Sino-US Trade War in The New York Times
}

\author{
Ruiqi Zhou ${ }^{1} \&$ Siying Qin ${ }^{2}$ \\ ${ }^{1}$ School of English for International Business, Guangdong University of Foreign Studies, Guangdong, China \\ ${ }^{2}$ SINA Corporation. Guangzhou, China \\ Correspondence: Ruiqi Zhou, School of English for International Business, Guangdong University of Foreign \\ Studies, Guangzhou, No. 2 Baiyun Avenue, China.
}

Received: August 16, 2020

doi: 10.5539/elt.v13n10p85
Accepted: September 1, 2020

Online Published: September 21, 2020

\begin{abstract}
Critical Discourse Analysis is an interdisciplinary approach to the study of discourse regarding language as a form of social practice. As a specific discourse, news discourse is a representation of the journalists' expression and construction of events, as well as readers' understanding and cognition of the events reported. It functions as a carrier that transmits ideologies and social values. Recently, news reports on the trade conflicts between China and the US has been the focus of world attention. A study of news reports on Sino-US trade conflicts with Critical Discourse Analysis approach helps interpret the relation between language use and social contexts and reveal ideological significance and power struggle in language. Twenty pieces of news reports on China's tariff actions on the United States, collected from The New York Times from 2018 to 2019 are studied and the result shows that the use of language in the news texts is not arbitrary, but rather dominated by the medium. The options of lexical expressions in news, the selection of clause types and the position of participants enable the medium to construct a negative image of China and to define China as an unfavorable country. The reasons deciding the language use in this discourse are the tension and balance of the power relation between the U.S. and China in the trade war, and the institution's favor of the American interest, the American political hegemony and the advocacy of force.
\end{abstract}

Keywords: Critical Discourse Analysis, Systemic Functional Grammar, Sino-US trade war, The New York Times

\section{Introduction}

Critical discourse Analysis (CDA) is an approach applied to a wide range of discourses to investigate the relation among discourse, ideology and power in sociocultural contexts. As one such specific discourse, news reports has always adhered to the objectivity of news, yet it is inevitable for news reporters to convey ideologies of a particular social group, thus generating impacts on readers' cognition and value. As van Dijk (1988) argues structures of news discourses can be explicitly linked to social practices and ideologies of news making and, indirectly, to the institutional and macro sociological contexts of the news media. So as a kind of mass media, news has the function of constructing meaning and is the reflection and mapping of social ideology. From the perspective of linguists, news is not just about reporting an event, but ideas that can be replaced by other terms like 'values', 'beliefs', 'theories', 'propositions', 'ideology' etc. (Fowler, 1991) For them, language in news is a highly constructive mediator instead of being neutral. News is seen as a representation of world realized by language which is not value-free. As a kind of social practice, news is utilized by newsmakers to implicitly convey various ideological meanings and unconsciously affect readers. And it is with this thought that a number of linguists use news reports as the main object of critical discourse analysis.

The object of critical discourse analysis for this research is the news reports concerning the trade war between China and the U.S. The Sino-US trade war started from March, 2018 when the U.S. President Donald Trump imposed tariffs on about USD60 billion worth of goods imported from China based on the "301" trade investigation on China. The "trade dispute" or "trade war" between the two largest economies in the world is now a hot topic in the world, attracting attentions from all walks of life, including various media in different countries, especially those in the two countries. As the voice power of America, the news reports on The New York Times are worth studying. So the purpose of this paper is to analyze the latest Sino-US trade war-related 
news reports on The New York Times within CDA framework with a view to learning about how language is used to produce the media discourses and revealing the medium's attitudes toward the trade war and its social ideologies behind the discourses.

\section{Literature Review}

\subsection{Development of Critical Discourse Analysis}

Scholars of CDA investigate how societal power relations are established and reinforced through language use, stressing the role of power in domains such as education, media, and politics. Fowler et al (1979) raise the term "Critical Linguistics" and suggest that there are strong and pervasive connections between linguistic structure and social structure. However, it differs from sociolinguistics in that sociolinguistics speaks only of the influence of social structure on the use of language. Critical linguistics suggests that language confirms and consolidates the organizations that shape it. These organizations use it to manipulate people, to establish and to maintain people in economically convenient roles and statuses, as well as to maintain the power of state agencies, corporations and other institutions (Fowler et al., 1979).

Another claim made by Halliday (1973) is that, since language is studied in contexts of interaction, and the structure of language in use is responsive to the communicative needs of these interactions, language structure should generally be seen as having been formed in response to the structure of the society that uses it. The interrelation of language structure and social structure is explained by Halliday as being reciprocal. Based on SFL theory and sociological theories, Fairclough (1989) argues that language is social practice instead of simple linguistic phenomenon that is independent from society. He believes that language should be studied as discourse, both in speaking and written forms. Fairclough (1992) proposes his three-dimensional model, which highlights the idea of discourse being a social practice, in which text is a product of discursive practice which includes production, distribution and consumption of the text. The text dimension and discursive practice dimension are confined by social practice. Discourse - language as social practice - is determined by social structure. Seeing discourse as a social practice is helpful for analyzing interrelations of texts, processes and context. Fairclough's CDA is apt to a sociological analysis of discourse because he absorbs a lot from methodologies and linguistic theories like systemic functional grammar, pragmatics, Western Marxism social criticism theory, in particular ideology theory, Foucault's power theory as well as theories about language and society of post-structuralism (Xin, 2007).

Different from Fowler and Fairclough, van Dijk studied critical discourse analysis on a basis of psycholinguistics and cognitive linguistics, stressing the media function of human mind in the relations of language use, context and social construction (Xin, 2007). Van Dijk (1984) puts forward the social cognitive model of discourse. He places particular emphasis on text linguistics and cognitive linguistics, and concentrated on analyzing discourses in a social cognitive approach. In terms of cognition, it's not hard to understand that this approach creatively introduces the study of cognition into the discourse analysis in the field of CDA by exploring the interrelationship of cognitive phenomenon and discourse structures, as well as social structures.

A review on the development of CDA enables us to understand that CDA doesn't deal with telling if language use in discourse is right or not. The central idea of CDA is to explore the relationship between text and the context in which it exists.

\subsection{Previous Studies on News Discourse Adopting CDA}

CDA approach has been largely adopted in the analysis of news discourse. Toward the end of the 1970s, the first critical study of mass media in linguistics was introduced by Fowler et al. (1979). Fowler (1991) claims that news is a practice: a discourse far from neutrally reflecting social reality and empirical facts, intervenes in the social construction of reality. His study explores how language structure serves to construct ideas and beliefs in news and emphasizes the linguistic devices for a critical analysis of discourse like lexical structure, transitivity, modality, and speech acts.

van Dijk (1988) tries to combine discourse analysis with media analysis for the first time, focusing on one of the most important types of discourse in mass media - news in newspaper. He tries to establish a link between news discourse and cognition and believes that without a cognitive theory of writing, reading and understanding news, it's difficult to understand what mass media is and what role it plays in shaping, confirming and changing our knowledge and attitude towards the world. van Dijk (1998) comes up with several analytical tools - script, macrostructure and news schemata - to analyze the cognitive processes of journalists and readers.

Fairclough (1995a) combines social theories with CDA to offer a new method for analyzing language use in news reports, which involves poststructuralist's interest in genre mixing and intertextuality, as well as concerns 
of modern social theory. In his investigations to texts, Fairclough (1992) shows that for any text, there is an assortment of other texts or voices may be incorporated into the text. This property of discourse is called intertextuality, which makes information or events represented in the text selective. By analyzing a report on extradition of two Libyans who are accused of being responsible for the Lockerbie bombing in 1988, Fairclough (2003) argues that an established structure helped to unfavorably interpret the Libyan side in the report. In other words, it seems that there is a hidden "antagonist-protagonist" structure that opposes the "good" western diplomats and politicians to "bad" Libyans.

Power (2018) critically studies how women are represented in three top-selling American business magazines between 2015 and 2017 by comparing the frequency with which men and women are mentioned; documents the level and types of behavior ascribed to women by using Halliday's transitivity analysis and van Leeuwen's representation of social factors framework. Her research conduces to a growing literature on media representations of women and advocates gender equality, presenting a new perspective and point of critical discourse analysis.

In China, Chen (1995) studies two news reports on strike in two English newspapers and concluded that news reporters utilize grammar, social relation and text structure to convey ideologies and realize its control over power. Hence, the analysis of news texts should be critical, so as to reveal the means of controlling ideology used by mass media.

Later, Xin (1996) conducts a critical discourse analysis of two news discourses to explain how ideology affects language use and how the power class uses language as a tool to spread and strengthen its ideology by controlling the media. Xin (2000) argues that news reports should be studied diachronically and synchronically in order to reveal the ideology inside.

By using the transitivity system of Halliday's SFG, Jiang and Gu (2000) study the ideological meaning contained in English news reports. It is found that the ideological meanings are embodied in the speaker's selection of transitivity system in news reports, and this selection process is influenced and restricted by the speaker's standpoints, communicative intentions and social context. By comparing the newspapers of China Daily with those of The New York Times, Liu (2008) carries out a statistical analysis of the use of modal verbs in China Daily's reporting of domestic news. It concludes that China Daily lacked the flexibility in the combination of modal verbs and reporting contents, which limited the negotiation and communications between the news discourses and readers in terms of interpersonal meaning, and weakened the readability and storytelling of news reports.

Dai (2015) conducts a critical analysis of English news discourse from the perspective of intertextuality, and states that news producers often indirectly express their thoughts and influence readers' views on the reported events by using different ways to represent speeches from news source. Liu (2018) employs dialectical-relational approach to conduct critical discourse analysis. Based on a self-built small corpus on Chinese smog reports, he studied Chinese and American media from four levels: word frequency, concordance, collocation and clusters. By conducting a comparative analysis, he concludes that The New York Times focused on rendering a negative image of China, while China Daily attempted to construct a responsible government who is earnestly carrying out its commitment of environmental governance.

Previous studies on CDA and its application in news discourse help manifest its validity and application as an analytical approach to news discourse. However, there are still some limitations. First of all, most of the news discourses researched with CDA are related to political, cultural or racial topics, few are on business events, especially on trade-related business events. Secondly, some of the analytical tools in CDA model, especially those to measure transitivity and modality are not explained in detail. To cover these gaps, the present authors intend to carry out a critical analysis of the latest Sino-US trade war-related news reports of The New York Times by combing Fairclough's CDA model with Halliday's Systemic Functional Grammar (SFG) theory.

\section{Theoretical Framework}

\subsection{Fairclough's CDA Model}

In order to examine the interrelations among language, ideology and power, Fairclough proposed a three-dimensional model, within which discourse involves text, discourse practice and social practice and three dimension of discourse analysis in accordance with them: description, interpretation, and explanation. 


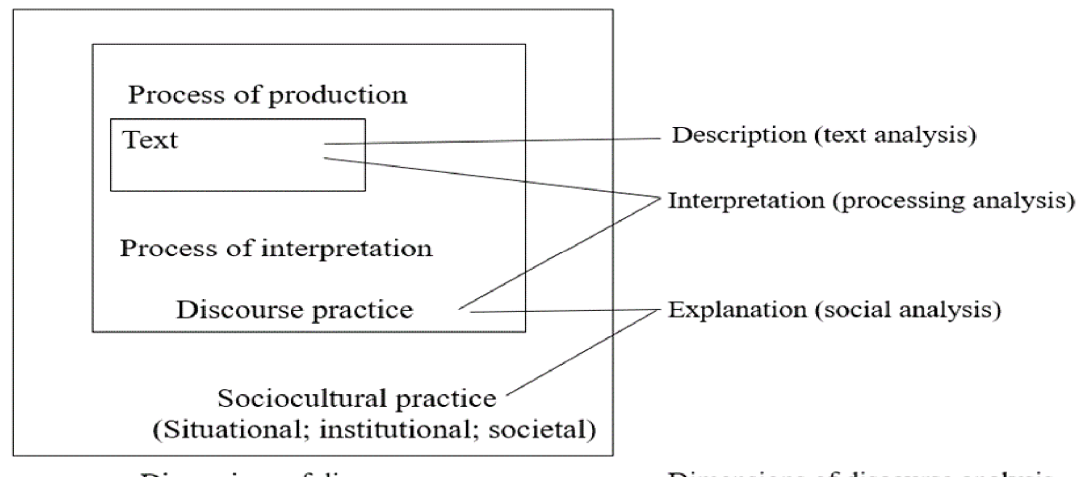

Dimensions of discourse

Dimensions of discourse analysis

Figure 1.The Three-Dimensional view of discourse analysis (Fairclough, 1995a, p.98)

It can be seen from the above Figure that discourse is a multidimensional synthesis involving three dimensions: text, discourse practice (text production and interpretation), sociocultural practice. Correspondently, discourse analysis can be made at three stages: text analysis (linguistic description of the text), processing analysis (interpretation of the relationship between the text and discursive processes, and social analysis (explanation of the relationship between the discursive processes and the social processes). (Fairclough, 1995b).

\subsubsection{Text Analysis}

Text analysis deals with formal properties of the text, which involves properties of vocabulary, grammar, textual structure and so forth. In analyzing vocabulary, the method "is based upon the assumption that different ways of lexicalizing domains of meaning may include ideologically different systems of classification, so there is an interest in how areas of experience may come to be relexicalized on different classificatory principles" (Fairclough, 1992, p. 28). This classification approach of vocabulary focuses upon experiential values reflected by lexical choices and classification schemes drawn upon in a specific text.

Clause is seen as the main unit of grammar in text analysis. In his introduction to systemic functional grammar (SFG), Halliday argues that transitivity "construes the world of experience into a manageable set of the clause" (2004:106), pointing to the ideational dimension of the grammar of the clause. Halliday's work in transitivity focuses upon the process, which is presented by verb phrases in clause, and includes the participants realized by noun phrases and pronounces, as well as the circumstances related with the process (typically realized by prepositional and adverbial phrases). Halliday identifies six processes types of the grammar of clause: material, mental, relational, verbal, behavioral and existential processes in accordance with whether the clause is the representation of action, speech, mental state or state of being. The options of the process types and the positioning of the participants involved in processes are closely related to the speaker's or writer's perceptions and understanding of reality. From this perspective, "transitivity has the facility to analyze the same event in different ways, which is of great interest in newspaper analysis" (Fowler, 1991, p. 71). One objective of analyzing transitivity in the present study is to figure out whether particular types of process and types of participants are favored in the texts and factors may account for that.

Another focus upon the grammar is modality. According to Halliday (2004), the clause of grammar is not only "representing certain process, but also a proposition, or a proposal, whereby we inform or question, give an order to make an offer, and express our appraisal of and attitude towards whoever we are addressing and what we are talking about" (p. 29). As Fairclough (1992) argues, the producer must indicate a degree of affinity with the proposition in any propositional utterance, and so any utterance has the nature of modality, or is modalized.

\subsubsection{Processing Analysis --- Intertextuality}

Processing analysis "specifies the nature of the processes of text production and interpretation, for example which types of discourse are drawn up and how are they combined" (Fairclough, 1992, p. 4). "It is this aspect of discursive processes - determining what aspects of members' resources are drawn upon and how - that is of most interest" (Fairclough, 1992, p. 80) in processing analysis. From this perspective, intertextuality is treated as a major focus of discursive processes.

Fairclough (1992) defines intertextuality as the productivity of texts - how texts can transform previous texts and rebuild existing conventions to produce new texts. Discourse representation, according to Fairclough (1992), is "a form of intertextuality in which parts of other texts are incorporated into a text and usually explicitly marked 
as such, with devices such as quotation marks and reporting clauses" (p. 107), for instance "she told" or "Jack claimed". It is a major part of news discourse: representations of what news worthy people have said.

One of the objectives for analyzing intertextuality is to specify what other texts are drawn upon in the constitution of the text being analyzed, and how. (Guo \& Liu, 2016). Hence, source and mode of discourse representation as the aspects of discourse representation are addressed in the present study. Newsworthy events usually originate from those "who have privileged access to the media, who are treated by journalists as reliable sources, and whose voices are the ones which are most widely represented in the media discourse" (Fairclough, 1992, p. 100). In this case, the medium has an impact on the ideological work of spreading the voices of power group in a disguised way and thus the options of source significantly affect the value of news reports. The mode of discourse representation is helpful for explaining a significant variable in the representation of discourse - the degree to which boundaries are maintained "between the voice of the person being reported and the voice of the reporter" (Fairclough, 1992, p. 107). The degree of "boundary maintenance", according to Fairclough, points to choices between direct and indirect discourse.

\subsubsection{Social Analysis}

Social analysis explores "the relationship between interaction and social context - with the social determination of the processes of production and interpretation, and their social effects" (Fairclough, 1989, p. 26). A piece of discourse is embedded within sociocultural practice at a number of levels: in the immediate situation, in the wider institution or organization, and at a societal level. Ideology and power issues may appear in each of these levels. And to discuss discourse and power in terms of hegemony (Fairclough, 1992) is useful for the analysis of these three levels of societal context.

\subsection{Analytical Framework for the Present Research}

The critical analysis of news discourse on Sino-US trade war follows the three-dimensional model constructed by Fairclough and Halliday's work in SFG. Discourse analysis will be carried out in terms of three dimensions: description, interpretation and explanation (see Figure 2 below), with a view to answer the three specific research questions: 1) What are the linguistic features in the news reports on Sino-US trade war from The New York Times? 2) How are these news reports interpreted in terms of intertextuality? 3) What are the social factors affecting the production and interpretation of these news reports?

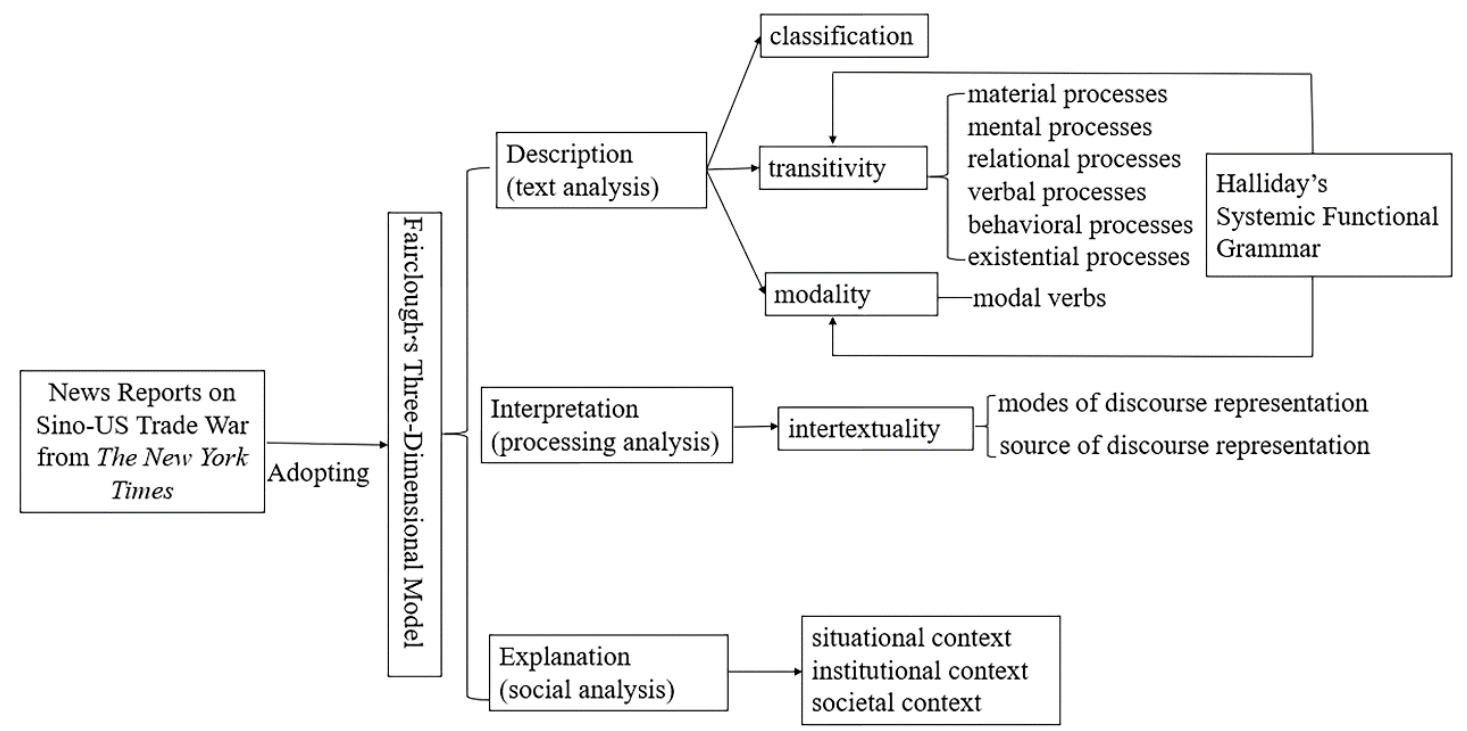

Figure 2. The analytical framework for the present research

\section{Methodology}

To answer our research questions, both qualitative and quantitative method are adopted. The news discourses for analysis are selected from The New York Times, a leading newspaper in the world since it "exhibits fragments of an overall American ideological perspective on news events and the world" (van Dijk, 1998:21) and is considered the representative voice power of the United States. In respect of the event for the present study, the Sino-US trade war is an issue that raises concerns and stirs panic worldwide in the field of economy, business and politics. Hence, there is no wonder that the trade war deserves in-depth investigations. 
Since this paper is to explore the medium's attitude towards the Chinese side in the trade war, the authors collect the news reports on the tariff measures taken by China in response to the United States. Hence, the author determines "tariff", "China", "the U.S.", "trade dispute", "trade war" as key words in the searching bar of the website of The New York Times. Twenty pieces of English news reports associated with China's tariffs on the United States are extracted, and used as linguistic samples in this study. To process the linguistic data, the corpus "Sino-US trade war in The New York Times" is built at first and the UAM Corpus Tool 3 is used for tagging the data.

\section{Analysis of News Reports on Sino-US Trade War from The New York Times}

\subsection{Description Stage}

Description stage (also known as text analysis) mainly concerns the formal properties of the news discourses, including lexical classification, transitivity and modality in news samples in The New York Times. The objective is to describe formal features in the news samples as particular choices from among the options of vocabulary and grammar.

\subsubsection{Classification}

Lexical Classification analyzes ways to name and represent people and events. The focus of wordings in news samples is to identify different meanings conveyed by the naming of the participants in the news reports, and the using of adjectives to describe China's response to the trade war in order to examine the reporters' attitude towards the person, or the event being referred to, and their impressions on the audience.

Re-classification is "relabeling, the provision of a new set of terms, either for the whole language or for a significant area of the language; it promotes a new perspective for speakers, often in specialized areas which are distinct from those of the larger social group" (Fowler et al., 1979, p. 211). Broadly stating, it is a naming strategy used by a speaker or writer to imply certain meaning and to impress audiences. Different naming of an entity may imply reporter's attitude towards it. In the news samples, the naming of China's state news media is noticeable:

Table 1. Naming of China's state news media in the news samples

\begin{tabular}{ll}
\hline Naming of China's state news media & Text \\
\hline State media outlets & Sample 1 \\
China's state-run news media & Sample 1, Sample 11 \\
China's state-controlled news media & Sample 15 \\
China's heavily controlled news media & Sample 1, Sample 15 \\
the official news agency & Sample 10 \\
the Communist Party's mouthpiece & Sample 1 \\
the state-run newspaper Global Times & Sample 1 \\
Global Times, a tabloid owned by the Chinese Communist Party & Sample 2, Sample 3 \\
Global Times, a nationalist tabloid owned by the Communist Party & Sample 15 \\
\hline
\end{tabular}

It can be seen that the naming of the China's state media undergoes some changes in the news samples, especially the naming of "Global Times". In Sample 1, "Global Times" is named as a state-run newspaper. However, it is called "a tabloid and a nationalist tabloid" in Sample 3 and Sample 15 respectively. A tabloid is often thought of as a newspaper less serious than others. And the use of "state-run", "heavily controlled", "mouthpiece" shows the reporters' stereotype of the Chinese media, providing readers an impression of the government's centralized control over the press in the country.

The focus now turns to over-classification, which means "a large number of synonymous or near-synonymous terms for communication of some specialized area of experience" (Fowler et al., 1979, p. 211). A striking instance is about adjectives found in the news samples. The adjectives employed to describe the Chinese side, including the description of China as one party in trade war, of its response, of its economic conditions and of its citizens etc., are shown in the table below: 
Table 2. Adjectives describing the Chinese in the news reports on trade war

\begin{tabular}{llll}
\hline Value of Meaning & Positive & Neutral & Negative \\
\hline & unafraid; polite; careful; & muted; neutral; & defiant; aggressive (3); weakening; \\
& calm; & unchanged; & not invulnerable; limited (2); \\
& unafraid & modest; & painful; \\
& polite; confident; & vital; not replaceable; weaker (2); slowing; unfair (5); & negative; defiant; trickier (2); \\
& confident; & planned; & reluctant; retaliatory; angry; \\
Adjectives & swift; & innocent; & invisible; unrealistic, difficult, not \\
& not afraid; & unusual; & doable; limited; confused; \\
& immediate; & & herculean (2); underdeveloped, \\
clearheaded; united; & & 34 & $60.72 \%$
\end{tabular}

The adjectives used for description of the Chinese side are shown in the above table. According to the results, the percentage of adjectives with negative meanings in news discourses is the biggest $(60.72 \%)$, followed by positive adjectives (23.21\%), and neutral adjectives accounts for the smallest percentage, (16.07\%). This indicates that adjectives used by the reporters are emotional or evaluative, which violates the principles of being objective and impartial for a medium in reporting news. More than half of the adjectives describing China in the table are unfavorable ones, which will undoubtedly create an undesirable image of the country. Examples of adjectives with negative meaning are presented below.

(1) China's economy has shown it is not invulnerable. (Sample 1)

(2) China's other options are limited ... (Sample 2)

(3) But a weakening Renminbi also creates an incentive for Chinese companies... (Sample 5)

(4) But a_weaker currency would make China's imports ... (Sample 17)

(5) It's unrealistic, it's difficult in practice, it's not doable, and it's against basic trade rules. (Sample 17)

"Not invulnerable" in Example (1), "limited" in Example (2), "weakening" in Example (3), and "weaker" in Example (4) can be seen as near synonyms repeatedly used to describe China. This way of over-classification seems to be linked to a preoccupation in the report with the ideological projection of a view of China as a vulnerable economy in a trade war. "It" in Example (5) refers to "Chinese tariffs on equal fractions of trade". Here, the medium uses derogative words "unrealistic", "difficult" and "not doable" to describe "it". These are typical instances of over-classification, which indicates the application of words with similar meanings to describe the same thing repeatedly and help the medium to construct a contrast between the two countries' tariff-based retaliation against each other.

To conclude the analysis of classification, the options of vocabulary is helpful to prove that language use is not neutral in the news. It is in fact a representation of the world dominated by the medium that creates so-called realities or facts. The employment of classification here helps the medium depict a not well-received image of the Chinese side, whose economic conditions are vulnerable due to the trade war.

\subsubsection{Transitivity}

Fowler (1991) argued that transitivity in Halliday's systemic theory of language lays the foundation for representation, and shapes the way the clause employed for analyzing events and situations as being of certain types. News discourses are abundant with instances of ideological significance of transitivity.

Table 3. Process distribution in news samples

\begin{tabular}{llllllll}
\hline Type of process & Material & Mental & Relational & Verbal & Behavioral & Existential & Total \\
\hline Number & 1472 & 154 & 308 & 377 & 8 & 20 & 2339 \\
Percentage & $62.93 \%$ & $6.58 \%$ & $13.17 \%$ & $16.12 \%$ & $0.34 \%$ & $0.86 \%$ & $100 \%$
\end{tabular}

It can be seen in Table 3 that material process accounts for the largest percentage (62.93\%) in the twenty pieces of news report, followed by the verbal $(16.12 \%)$ and relational process $(13.17 \%)$. The medium - The New York 
Times -relies mainly on material and verbal process to report Chinese tariff sanctions on the United States in the trade war. Material clauses express the process of doing, meaning that certain entity does something, extended to another entity or other entities. Since newsworthiness usually comes from a set of people who are regarded by journalists as reliable sources, verbal clauses are commonly seen in news discourses. Relational clauses are processes of characterizing and identifying of events or people involved in news. Mental process helps people to express their feelings, perceptions or cognition of a specific event or thing. Note that processes of feeling are usually subjective, so mental process is less likely than material process to appear in news texts. In the case of behavioral and existential clause, the former expresses human psychological and physiological behavior; the latter represents the existence or happening of something. The news reports on the Chinese tariff measures to counter against sanctions of the U.S. mainly concentrate on representing actions taken by the Chinese government in the "event" - the Sino-US trade war, rather than representing personal feelings or existence of something. Hence, behavioral and existential processes rarely appear in the selected news reports. In the following part, these two types of clauses will not be further discussed, whereas material, verbal, relational and mental clauses will be examined with specific examples.

Material process

As a process of doing, material clause usually includes the Actor who carries out the action, and the Goal at whom the action is directed. Reporters need to inform the readers what both sides of the trade war have done to each other, and thus material processes are the best options for the medium to represent their 'doings'. The Actor in the material processes is also noteworthy. In Examples below, clauses that are particularly of ideologically significance are underlined, and participants in material process are labeled.

(6) China's decision to impose tariffs on soybeans squeezes some of Mr. Trump's staunchest
Actor
Process
Goal

supporters across the Midwestern farm belt. (Sample 6)

(7) As China swallows the world's supply of non-American soybeans, other countries are buying

Actor Process Goal

more beans from the United States... (Sample 6)

The above two processes both represent the "doing" of Actors: "China's decision" in Example 6, "China" in Example 7, demonstrating the function of material process to represent actions taken by the parties involved in the trade dispute. The material clause in Example 6 represents decision made by China as a means to suppress the Goal "some of Mr. Trump's staunchest supporters", who are the American farmers, with "squeezes" serving as the Process. In Example 7, the Actor "China" is represented as a predator who "swallows" (the Process) resource from other countries, and the Goal is "the world's supply of non-American soybeans". These two material processes are used to give a presentation of China's image in the trade war and represent China as being aggressive and active in the trade war.

Verbal process

Verbal process refers to the process of saying which includes Sayer, Receiver and Verbiage as participants. Verbal clauses account for $20.84 \%$ in the news reports collected from The New York Times. There are verbal clauses in which the verbiage gives a presentation that China is playing a damaging and negative role in the bilateral trade between the U.S. and China. For example:

(8) "China is our real trade enemy, and their theft of intellectual property and their refusal to let our companies compete fairly threatens millions of future American jobs," Mr. Schumer said.

$$
\text { Verbiage Sayer Process }
$$

(Sample 9)

The Sayer "Mr. Schumer" in Example 8 is the Senator Chuck Schumer of New York, the Democratic leader, with "said" being the Process. The verbiage of the Sayer constructs an image of China - a real enemy of the United States - who acquires technological intellectual property from the U.S. through threat and oppression, which seems to be unwelcomed and unfavorable.

Mental process

Mental process is the process of representing the mental world or the conscious world. There are mental clauses in the news samples transmitting the feelings of Chinese citizens, businessmen and others affected by the trade war, for instance: 
(9) ... but is being led instead by traders in currency markets, who are increasingly worried about

Senser

China's slowing economy and huge debt burden.

Phenomenon
Process

(Sample 7)

The mental process in Example 9 is realized by the Process "are increasingly worried about", and the Senser "traders in currency markets". These two mental clauses show business people's concern about the Chinese market. It is noted that the verb group of the Process in Example 9 presents the increasing negative emotion of the Senser toward the Phenomenon (China's slowing economy and huge debt burden). An unstable economic condition or an economic downturn in China is constructed in this process.

Relational process

Relational processes are mainly used to describe the 'being' of China in the trade dispute. What follows is a typical example of relational processes extracted from the news samples.

(10) Still, China's economy has shown it is not invulnerable. (Sample 1)

\section{Carrier Process Attribute}

Relational processes are underlined in the above Example. The Carrier "it" (China's economy) has an Attribute "not invulnerable" ascribed to it. Here, a double negative Attribute intensifies the medium's negative evaluation of China's economy.

\subsubsection{Modality}

Modality system deals with the extent to which news reporters commit themselves, or conversely distance themselves from propositions. To determine the medium's degree of affinity expressed with propositions in news samples, the focus upon modal verb (a feature of modality) in this section is used to assess the importance of modal verb for social relations in the news and controlling representations of reality. According to Halliday (2004), modal verbs are regarded as a set of 'modal operators' or 'the Finite verbal operators', which serve as the finite element in clauses, namely, they have the function of making the proposition finite. The following are modal verbs in clauses that may express the reporter's degree of affinity with propositions.

(11) For all its economic might, China hasn't been able to solve a crucial problem. (Sample 19)

(12) It just can't grow enough of them. (Sample 19)

"Hasn't been able to" and "can't" (in Examples 11 and 12 respectively) on their own are of high value, and negate propositions with their negative meaning. The reporters' degree of affinity is high with the propositions. The propositions are: "China is able to solve a crucial problem" (cultivating soybeans by itself) in Example 11; and "It grows enough of them" ("it" refers to "China", and "them" refers to "soybeans") in Example 12. It is not clear whose perspective is being presented. The medium may shape its own perspective into a universal one, or it may function as a carrier for the perspective of other individual or group. In either case, the modality made in the two examples implies a form of power struggle between China's capacity of producing soybean and its soybeans dependence on the U.S.

\subsection{Interpretation Stage - Intertextuality}

The stage of interpretation is to examine the production and interpretation processes of news discourse in terms of intertextuality. Reporters are confronted with many choices in the process of producing news. This stage focuses upon what other texts are drawn upon in the construction of news discourse and how. The voices represented in news reports are treated as discourse representation, a form of intertextuality. The analysis of discourse representation contributes to discovering traces of sources of texts incorporated into the news discourse and how they are used to generate the news discourse. As the aspects of discourse representation, source and mode are focuses at this stage.

\subsubsection{News Source}

For reporters, a 'source' can be a person, an institution, or a document, which provides reporters with timely and newsworthy information. Zhang (1994) distinguished news source into three types: specified, semi-specified and unspecified sources. Specified source refers to the one whose detailed information such as name, position, etc., is made explicit in the news. With regards to semi-specified source, its information is not stated in detail but along with a hint (the name of an organization, or a group), for example, "Economists say...". Unspecified sources are adopted when newsmakers are not sure of the specific information of source or they want to hide it for certain 
purpose, such as "it is reported that..." The distribution of the three types of news sources in news samples is shown in the table below.

Table 4. The distributions of news sources in the news samples

\begin{tabular}{lllll}
\hline Text & Specified Sources & Semi-specified Sources & Unspecified Sources & Total \\
\hline Total & 91 & 60 & 0 & 151 \\
Percentage & $60.26 \%$ & $39.74 \%$ & 0 & $100 \%$ \\
\hline
\end{tabular}

From Table 4 it can be seen that specified source accounts for the highest proportion among the three types of news source, and no unidentified source is used in the news discourses. The employment of specified source is helpful for reflecting authority and credibility of the news reports. As Ku (2004) states, it enables the reporter to present himself as being objective and reliable in producing news. If we make a meticulous observation on the newsworthy information source, most specific sources are mainly occupied by the American officials and citizens who are making complains about the Sino-US trade relation and support the trade war. By choosing negative voices about the Chinese side as specific source (i.e. "China is our real trade enemy, and their theft of intellectual property and ..." from Mr. Schumer), the medium intends to implant its own views that the trade relation between the two countries is unfair and China behaves badly in the trade transactions, leading to the growing of people's opposition to the Communist Party.

What's more, it should be noticed that more than one third of news sources are semi-specified. If the news sources are not identified clearly, the authenticity of reports may be negatively affected since it gives readers an impression of vagueness. According to Edelman (1977), sometimes reporters will deliberately conceal the source for some reasons, which is called as "reference to mythical groups". The purpose of employing "reference to mythical groups" is to publicize and reinforce reporter's standpoints (Xin, 2005). From this perspective, options of semi-identified sources are ideologically significant, helping to interpret the news discourse from a new perspective, for instance:

(13) China's responses have so far failed to thwart Mr. Trump's trade offensive... Chinese leaders aren't sure how to respond, people briefed on economic policymaking discussions say. (Sample 17)

The source in Example (13) is semi-specified as "People briefed on economic policymaking discussions" is a vague expression. This group of people is familiar with economic policymaking. Their discourse represented in the news indicates China's inability to fight against the Trump administration. On the one hand, the medium may attempt to convey its own idea or comments by reporting the voices of this group, so as to demonstrate China's limited capabilities when faced with the trade war. On the other hand, the use of such vague expressions negatively affects the authority of the information in the news.

\subsubsection{Modes of Discourse Representation}

Options of different modes of discourse representation enable reporters to intervene in the words of others to varying degrees (Xin, 2005). News reports are full of various forms of direct and indirect quotations. The objective of the analysis of mode of discourse representation is to examine how newsmakers turn to other's utterances to produce news reports and how news reports are interpreted according the options of the medium. Fairclough (1992) has classified mode broadly into two types: direct discourse and indirect discourse. Direct discourses are represented in quotation marks indicating that they are those of the original. Direct speech often uses the original utterances of those who are reported. Hence, the words of the one reported and the words of the reporter are demarcated by a clear boundary. Quotation marks are omitted in indirect discourses, and the discourse represented is realized by a clause subordinated to the reporting clause in grammar, a relationship marked by the conjunction "that". Using indirect speech usually means that reporters only report the propositional content. According to Fairclough (1992), the boundary between the words of the reported and the words of the reporter is less explicit, and the language employed to show the former's discourse is likely to be those of the latter.

In addition to the above two types of reported speech, preset direct discourse was put forward by Volosinov (1973), in which indirect speech slips into direct speech. For example, He castigated the Finance Ministry instead for a "dearth of effective fiscal policies," referring to extra government spending and tax cuts. In this example, the reporter firstly adopts indirect speech and then slips to direct speech. It is a half narrative and half reported speech, and it presents the context of the direct speech. By employing this reporting mode, reporters mix their voices with the reported voices. As a result, the boundary becomes obscured. The proportion of modes of discourse representation and examples are presented below. 
Table 5. Distribution of modes of discourse representations

\begin{tabular}{lllll}
\hline Text & Direct Discourse & Indirect Discourse & Preset Direct Discourse & Total \\
\hline Total & 104 & 112 & 31 & 247 \\
Percentage & $42.11 \%$ & $45.34 \%$ & $12.55 \%$ & $100 \%$
\end{tabular}

It is shown in Table 5 that the indirect discourse accounts for $45.34 \%$ among the three modes of discourse representation followed by direct speech $(42.11 \%)$ and preset direct speech $(12.55 \%)$. Direct speech is more expressive in that the boundary between the utterances of the person reported and the utterances of the medium helps maintain the information original. Whereas the use of indirect speech and preset direct discourse may provide more opportunities for reporters to add their own comments or attitudes to other's voice. Hence, both indirect discourse and preset direct discourse can be treated as a blend of two voices. The present researchers have carried out an investigation into these two types of reporting mode in an attempt to find out how the medium intervenes its own ideas with other's voices in the process of news production.

There are indirect discourses in which the media add their own explanations to the end of the indirect discourses, helping the medium to intervene in the original voices to a higher degree, for instance:

(14) Many companies in Europe and the United States say they fear the program will create state-supported competitors, an argument that has won backing in the Trump administration. (Sample 12)

The part in bold in the above example is the extension or further explanation of the previous words. But it may not be easy for readers to judge whether they come from the news source or the newsmaker. It helps the medium blends its own voices with voices from "many companies in Europe and the United States" to further intensify the negative attitude towards "the program" ("Made in China 2025 program", a strategic plan aiming to move away from being the "world's factory" to producing higher-value products and services.), taking the side of the Trump administration.

According to Fairclough (1992), expressions in scare quotes (preset direct discourse) can be used to establish them as an outside voice, or to distance the medium from the outside voice, or to use its authority to support reporter's position. For instance:

(15) Mr. Trump said that the trade talks between the United States and China in Shanghai this week were "constructive" and that he looked forward to more "positive dialogue" between the countries. (Sample 4)

In the above example, discourse representation originates from Mr. Trump, among which "constructive" and "positive dialogue" are specially marked with quotation marks, indicating that they are Trump's original words. Both of them point to Trump's comments and expectations on Sino-U.S. trade negotiations, and both are positive. The reporters particularly marked them, either due to their disagreement with them, or their emphasis on them. No matter what the purpose is, it shows that reporters are not completely neutral when reporting news and the process of production is of ideological significance.

\subsection{Explanation Stage}

At the explanation stage, discourse is regarded as a social practice. The analysis of the discourse at this stage is closely related to the social background in which the text is produced. Since discourse is a social practice, it is of great importance to figure out its social background to better understand the ideological meaning in the news discourse. Therefore, this section deals with the analysis of the social factors that affect the production of the news discourses.

First of all, it is clear that China's tariff against the United States is part of the Sino-US trade war. Therefore, the immediate social context of the news discourses on China's tariff measures is the trade war, which is easy to find out by reference to the headlines from the news reports, like the headline "China Strikes Back at Trump's Tariffs, but Its Consumers Worry" in Sample 15, gives readers an impression that the Chinese consumers are at odds with the Chinese government, and indicates that the Chinese consumers may be negatively affected by the actions taken by the government. In Sample 13, when it comes to China applying to the W.T.O. for a legal measure to impose tariff products of the United States, the medium employs such wording as "the Trump administration has embraced other W.T.O. rulings in the favor of the United States...", showing the U.S. government's contempt for W.T.O. ruling against the interests of the U.S. will not be complied by the administration. This reflects the American hegemony, and disrespects for the independence and sovereignty of other countries. The influence of such hegemony on the news production can be observed by taking a look at the discourse representation appear in the news samples, such as "while many of our companies are hurt by the tariffs and ongoing trade tensions, we understand the U.S. government's frustration..." in Sample 1. We can see 
that the medium takes the American side and repeatedly refers to the opinions and attitudes from those who support and understand the actions of the U.S. government. Hence, the processes of production and interpretation of the news samples are influenced by the American hegemony. It seems that any action that serves to protect the interest of the United States, even a trade war between the world's two biggest economies is favored.

The medium in this case, The New York Times ranks among the top three newspapers in the United States today. According to Zhang (2014), media is an economic concept in the U.S. From this perspective, news is the product, and a medium is the company. This attribute of the American medium allows it to defend the interests of its own company and interest groups behind it, in particular when the events reported is associated with its economic foundation. Therefore, although the media claim to be independent of the government and political parties, advocating objectivity and justice and pursuing facts, in many cases, the "facts" they describe may not be true, and the justice may not be objective. For instance, in Sample 12, "some companies say that Beijing finds ways to force them to hand over technology if they want to sell their wares in China", is an example of discourse representation used to generate the news reports, which represent an aggressive and unfriendly image of China. The news source "some companies" in this example is vague expression without pointing out the specific source. Even though the use of this type of news source may negatively influence the authenticity and authority of the news reports, the medium still adopts it to generate the news and convey the points or ideologies of these groups.

\section{Discussion and Conclusion}

This study examined how language is use in the news and how it is affected by the newsmakers' ideologies in the news reports on China's tariff on the United States. At interpretation stage, it is found that the classification of words contributes to the representation of the Chinese media and the country. It provides the medium The New York Times with chances of representing China as a "centralized", and "undesirable" state in the news discourses. Transitivity provides different process types and associated participants as options. The options of clause types and the positioning of participants enable the medium to construct a negative image of China and represent China as an unfavorable country. In terms of modality, the newsmakers employ modal auxiliary verbs such as "hasn't" and "can't" to show its high degree affinity of modality with propositions, implying a form of power struggle between China's capacity of producing soybean and its soybeans dependence on the U.S. This once more confirms that "News is a representation of the world in language, because language is semiotic code. It imposes a structure of values, social and economic in origin, on whatever is represented; and so inevitable news, like every discourse, constructively patterns that of which it speaks" (Flower, 1991: P.4).

At the interpretation stage, news discourses are interpreted as discursive processes in terms of intertextuality. The intertextual analysis is realized by investigating news source and mode of discourse representation. News sources reflect the power relations in a way that over half of the specific sources are from the American side. And the employment of semi-specific source and unidentified source helps the medium create a negative image of China. As for the mode of discourse representation, reporter's indirect discourse accounts for the largest proportion, which provide the reporters with opportunities to incorporate their own voices into the news reports. This reflects reporters' control over the production of the news reports. The investigation of intertextuality reveals that it is the medium who dominates the processes of production and interpretation of news discourses and determines whose voices are represented and quoted in the news, and stresses their own comments or standpoints by identifying or blurring the news sources. Furthermore, they can add their voices into news discourse by adopting different modes of discourse representation. Their options in producing news give insight into ideological significance made explicit or implicit in news, such as highlighting the voices in favor of the U.S. side.

At explanation stage, it is found that the options made in the process of producing news reports can be affected by the tension and balance of the power relation between the U.S. and China in the trade war. The New York Times' favor of the American interest determinates its linguistic stance in the news reports. In a more macro perspective, the American hegemony and the advocacy of force also result in language use in news samples more like a contrast of power and strength between the two countries rather than an objective and fair covering of the event. In order to explain the options made by the medium in the process of news production, we shall take notice of the macro social context in which the news discourses are produced. Reporters' positions and ideologies heavily influence the production of news reports. (Yang, 2016)

The present study is conducive to inspiring readers to be cautious about ideology penetration when reading news reports. It provides readers with insights into how to enhance critical awareness and construct their own criterion concerning the Sino-US trade war. 


\section{References}

Chen, Z. Z. (1995). Discourse and Ideology: Critical Discourse Analysis. Journal of Foreign Languages, 97(3), 42-45. https://doi.org/CNKI:SUN:WYXY.0.1995-03-009

Dai, L. Q. (2015). Critical Discourse Analysis of Reported Speech in English News Discourse. Journal of Hunan Post and Telecommunication College, 14(1), 85-88.

Edelman, M. (1977). Language and Politics. New York: Academic Press.

Fairclough, N. (1992). Discourse and Social Change. Cambridge: Polity Express. https://doi.org/10.2307/2074659

Fairclough, N. (1995a). Critical Discourse Analysis: The Critical Study of Language. London and New York: Longman. https://doi.org/10.1016/0378-2166(96)89194-6

Fairclough, N. (2003). Analyzing Discourse: Textual Analysis for Social Research. New York: Routledge. https://doi.org/10.4324/9780203697078

Fairclough, N. (1989). Language and Power. London: Longman.

Fairclough, N. (1995b). Media Discourse. London: Edward Arnold. https://doi.org/doi:10.1146/annurev-anthro-091908-164450

Fowler, R. (1991). Language in the News: Discourse and Ideology in the Press. London: Routledge. https://doi.org/10.1109/MS.2006.107

Fowler, R., Hodge, B., Kress, G., \& Trew, T. (1979). Language and Control. London: Routledge and Kegan Paul. https://doi.org/10.1080/15295038809366686

Guo F., \& Liu K. (2016). A Review on Critical Discourse Analysis. Theory and Practice in Language Studies, 6(5), 1076-1084. https://doi.org/10.17507/tpls.0605.23

Halliday, M. A. K. (1973). Explorations in the Functions of Language. London: Edward Arnold. https://doi.org/10.1037/017051

Halliday, M. A. K. (2004). An Introduction to Functional Grammar. London: Arnold. https://doi.org/10.2307/4167892

$\mathrm{Ku}, \mathrm{M}$. (2004). Language and ideology: a critical study of political news discourse on Iraq War. (Unpublished master dissertation). Guangdong University of Foreign Studies, Guangzhou, China

Liu, L. H. (2008). An Analysis of Modal Verbs in Media Discourse. Journal of Tianjin Foreign Studies University, 15(5), 21-29.

Liu, N. (2018). A Corpus-based Contrastive Study of the Reports on the Haze in China. Journal of Beijing International Studies University, 265(5), 37-53.

Power, K. (2018). Women in Business Media: A Critical Discourse Analysis of representations of women in Forbes, Fortune and Businessweek, Critical Approaches to Discourse Analysis Across Disciplines, 11(2), $1-24$.

Van Dijk, T. A. (1984). Prejudice in Discourse. Amsterdam: John Benjamins Publishing London \& New York: Routledge. https://doi.org/10.1075/pb.v.3

Van Dijk, T. A. (1988). News as Discourse. New Jersey: Lawrence Erlbaum Associates. https://doi.org/10.1002/9781405186407.wbiecn020

Van Dijk, T. A. (1998). Opinions and Ideologies in the Press. In A. Bell \& P. Garrett (Eds.), Approaches to Media Discourse. Oxford: Blackwell. https://doi.org/10.1080/13520529509615438

Volonsinov, V. N. (1973). Marxism and the Philosophy of Language. New York: Seminar Press. https://doi.org/10.1007/BF00630629

Xin B. (2000). Critical Linguistics and Critical Analysis of English News. Foreign Language Education, 21(4), 44-48. https://doi.org/CNKI:SUN:TEAC.0.2000-04-009

Xin, B. (1996). Language, Power and Ideology: Critical Linguistics. Modern Foreign Languages, 71, 21-26.

Xin, B. (2005). Critical Linguistics: Theories and Application. Shanghai: Shanghai Foreign Languages Education Press. 
Xin, B. (2007). The Social and Cognitive Orientations of Critical Discourse Analysis. Foreign Language Research, 6, 19-24. https://doi.org/ 10.3969/j.issn.1005-7242.2007.06.004

Yang, N. (2016). Concepts, Perspectives and Topics in News Discourse Analysis. Modern Foreign Languages, 39(5), 714-723.

Zhang, G. Q. (2014). The Control of Media Discourse by American Interest Groups. Red Flag Manuscript, 9 , 34-37.

Zhang, J. (1994). Journalistic English: Style and Analysis. Shanghai: Shanghai Foreign Language Education Press.

\section{Copyrights}

Copyright for this article is retained by the author(s), with first publication rights granted to the journal.

This is an open-access article distributed under the terms and conditions of the Creative Commons Attribution license (http://creativecommons.org/licenses/by/4.0/). 